We used electrophysiologic criteria to identify median mononeuropathy (MM) at the nondominant wrist among 414 patients enrolled in a multicenter study of patients with mild diabetic neuropathy according to consensus recommendations. Patients with absent sural or peroneal responses or greater than mild symptoms of carpal tunnel syndrome were ineligible. Ninety-five of 414 participants $(23 \%)$ fulfilled criteria for $\mathrm{MM}$, independent of diabetes type. Patients with MM had a longer duration of diabetes than remaining patients, independent of age, and patients with $\mathrm{MM}$ and type II diabetes were more likely to be female (34\% vs. $19 \% ; P=0.008)$, shorter (165.7 vs. $172.7 \mathrm{~cm} ; P=0.001)$, and have a higher body mass index (32.5 vs. $29.1 ; P=0.0008)$ than remaining type II patients. Sural or peroneal conduction abnormalities did not influence the frequency of MM. These results suggest that patients with diabetic neuropathy require special consideration with regard to the evaluation of suspected carpel tunnel syndrome. (C) 1996 John Wiley \& Sons, Inc.

Key words: diabetes mellitus • diabetic neuropathy $\cdot$ nerve conduction studies - carpal tunnel syndrome - median mononeuropathy - multicenter study

MUSCLE \& NERVE 19:140-146 1996

\title{
FREQUENCY OF MEDIAN \\ MONONEUROPATHY IN PATIENTS WITH MILD DIABETIC NEUROPATHY IN THE EARLY DIABETES INTERVENTION TRIAL (EDIT)
}

\author{
JAMES W. ALBERS, MD, PhD, MORTON B. BROWN, PhD, \\ ANDERS A. F. SIMA, MD, PhD, and DOUGLAS A. GREENE, MD, FOR THE \\ TOLRESTAT STUDY GROUP FOR EDIT (EARLY DIABETES INTERVENTION TRIAL)
}

The lifetime risk of developing carpal tunnel syndrome (CTS), a commonly identified mononeuropathy, is approximately $10 \% .^{21}$ The clinical diagnosis of CTS depends upon a combination of appropriate clinical symptoms, with or without associated signs. Because symptoms associated with a variety of musculoskeletal disorders mimic those of CTS, most clinicians require electrophysiologic

From the Departments of Neurology (Dr. Albers), Biostatistics (Dr. Brown), Pathology (Dr. Sima), and Internal Medicine (Drs. Greene and Sima), University of Michigan Medical Center, Ann Arbor, Michigan.

Presented in part at the annual scientific meeting of the American Association of Electrodiagnostic Medicine, Montreal, Canada, September 23, 1995

Acknowledgments: Supported by Wyeth-Ayerst Research. The authors thank lisoon Yang for performing statistical analyses and preparing the tables for this study

Address reprint requests to Dr. James W. Albers, Department of Neurology, 1914 Taubman Center, University of Michigan Medical Center, Ann Arbor, Ml 48109-0316

Accepted for publication September 5, 1995

CCC 0148-639X/96/020140-07

(c) 1996 John Wiley \& Sons, Inc confirmation of a median mononeuropathy at the wrist (MM) before establishing a diagnosis of CTS. Nevertheless, use of increasingly sensitive criteria results in an increased frequency of false-positive results. ${ }^{20}$ The prevalence of $\mathrm{MM}$ is higher in diabetic patients, ${ }^{12}$ but this finding is not thought to influence the electrodiagnostic criteria of CTS. ${ }^{15}$

We report the frequency of MM in a population of patients with types I and II diabetes and mild diabetic neuropathy participating in a multicenter study. We used absolute median motor and sensory distal latency criteria, combined with the difference between median and ulnar sensory distal latencies (relative to criteria) to identify MM. The relative criteria are thought to be less sensitive to factors such as age, temperature, and anthropometric characteristics because individual median and ulnar nerves share the same general environment, differing only in their location relative to the carpal tunnel. We also investigated the relationships between the relative risk for MM and factors thought to be associated with increased risk for 
development of CTS, including body mass index (BMI) and lower limb nerve conduction results suggestive of generalized neuropathy. ${ }^{24}$

\section{METHODS}

Study Design. All patients were enrolled in a large, double-blind, placebo-controlled randomized study of the effects of tolrestat in patients with diabetic neuropathy. The trial design is described elsewhere. ${ }^{19}$ All data were collected prior to randomization and initiation of therapy.

Patients. Eligibility required types I or II diabetes mellitus as classified by the National Diabetes Data Group. ${ }^{18}$ Diabetic neuropathy was defined as a distal symmetric sensorimotor polyneuropathy using recommendations of the San Antonio Conference on Diabetic Neuropathy. ${ }^{4}$ Exclusions included a glycosylated hemoglobin less than $6.7 \%$ at the initial evaluation, a systemic illness other than diabetes associated with neuropathy, familial neuropathy, and a mononeuropathy other than a mild CTS (based upon the clinical experience of the examining neurologist). Patients with severe neuropathy were excluded by requiring recordable sural and peroneal responses. The diagnosis of clinically evident or subclinical diabetic neuropathy was based upon two or more abnormalities from the categories of symptoms, signs, electrodiagnostic studies, and quantitative sensory testing. Symptom and disability assessments were used to score symptoms and signs. ${ }^{10}$ Symptoms had to be consistent with a symmetric sensory or sensorimotor neuropathy. Nerve conduction abnormalities used to assess diabetic neuropathy were based upon sural and peroneal (not median) measures. Vibration perception threshold was measured at the great toe using a two-alternative forced-choice procedure; patients with a substantially elevated threshold were ineligible. Height and weight were measured, and BMI was calculated as weight $(\mathrm{kg}) /[\text { height }(\mathrm{m})]^{2}$. Subgroups based upon the BMI were created as follows: slender, BMI < 20; normal, BMI 20-24; heavy, BMI 25-29; and obese, BMI $\geqslant 30 .^{5}$

Nerve Conduction Measures. At 41 centers, electromyographers used techniques recommended by the Conference of Standardized Measures in Diabetic Neuropathy to evaluate dominant peroneal, nondominant median motor and sensory, and bilateral sural responses. ${ }^{6}$ The peroneal and sural recording techniques are described elsewhere. ${ }^{19}$ Median motor and sensory conduction studies used conventional techniques of supramaximal stimulation and surface recording. Upper extremity limb temperatures were maintained above $32^{\circ} \mathrm{C}$, recorded over the midpalm. Hand temperatures measured before and immediately after completing the conduction study were averaged and did not differ by diabetes type or gender.

Median motor onset latency was recorded using a distance of $7 \mathrm{~cm}$ from stimulation to recording electrode (wrist to thenar recording site). Antidromic sensory peak latency was measured using a stimulation to recording electrode distance of 14 $\mathrm{cm}$ (wrist to index finger). If the median motor latency exceeded $4.4 \mathrm{~ms}$ or the median sensory latency exceeded $3.8 \mathrm{~ms}$, an antidromic ulnar sensory peak latency (wrist to digit $\mathrm{V}, 14 \mathrm{~cm}$ ) was recorded to apply the relative criteria. Patients had three evaluations approximately 1 week apart before beginning therapy. Because most clinical decisions are based upon a single electrodiagnostic evaluation, we established the diagnosis of MM using results from the first complete evaluation. $\mathrm{Pa}-$ tients were included if their absolute criteria were normal or, if abnormal, the relative criteria were evaluated. A total of 389 studies were included from the first visit and another 25 were included from the first subsequent visit for which data collection was complete. Another 15 patients had incomplete data at all three visits and were excluded from all analyses.

Two criteria for the diagnosis of MM were evaluated. Both required an absolute prolongation of median sensory or motor latencies ( $>3.8$ and 4.4 ms, respectively). ${ }^{1,22}$ In addition, the first criterion required a difference between the median and ulnar sensory peak latencies exceeding $0.5 \mathrm{~ms}$. This relative difference is used conventionally in the diagnosis of $\mathrm{MM}^{1,14,16}$ and represents the 95th percentile for asymptomatic subjects without exposure to cumulative trauma. ${ }^{22}$ The second criterion required a relative median to ulnar sensory latency difference exceeding $0.8 \mathrm{~ms}$. This more conservative criterion represents the 99 th percentile for asymptomatic subjects without exposure to cumulative trauma. ${ }^{22}$

Statistical Analyses. Summary statistics are presented as the median and the 5th and 95th percentiles. Means of groups were compared by a two-sample $t$-test, after transformation where indicated; $P$-values in the tables are the results of comparing normals to abnormals separately within each diabetes type. When two proportions were compared, Fisher's Exact Test (two-tailed) was used. When more than two proportions were com- 
pared, a linear trend in the proportions was tested by the Mantel-Haenszel chi-square statistic.

\section{RESULTS}

The characteristics of the diabetic patients have been described previously for the entire cohort. ${ }^{2}$ Patients with type II diabetes were significantly older and heavier and had a higher BMI than type I patients, but the duration of symptomatic neuropathy and glycosylated hemoglobin levels were similar. The male patients were heavier and taller than the female patients but had a similar BMI.

Based upon the absolute criterion of a prolonged median sensory or motor distal latency, 138 of the 414 patients (33\%) demonstrated an abnormal result. Most abnormalities resulted from a prolonged median sensory latency, with or without prolongation of the motor latency; only 6 patients had a prolonged median motor but normal median sensory latency. According to the additional conventional criteria for $\mathrm{MM}$, which included a median minus ulnar sensory latency $>0.5 \mathrm{~ms}, 95$ (23\%) of 414 participants continued to be abnormal. When the more conservative relative criterion of a median minus ulnar sensory latency $>0.8 \mathrm{~ms}$ was used, $68(16 \%)$ of 414 participants fulfilled the criteria for MM. Of the 6 patients with a prolonged median motor but normal median sensory latencies, only 1 had a relative prolongation of the median sensory latency compared to the ulnar sensory latency.

The characteristics of patients fulfilling conventional criteria for MM are compared with those of the remaining patients in Table 1 . The data are shown separately for patients with type I and type II diabetes mellitus. Although type II patients were older than type I patients, the frequency of MM was similar in the two groups. Within each group, there was no significant difference in age between patients with and without MM. Patients with $M M$ had a longer duration of diabetes mellitus than patients without MM (type I, 22.5 vs. 16.0 years, $P=0.003$; type II, 8.8 vs. 7.0 years, $P=$ 0.034). Type II patients with MM were shorter $(165.7$ vs. $172.7 \mathrm{~cm} ; P=0.001)$ and had a higher BMI (32.5 vs. $29.1 ; P=0.0008$ ) than the remaining type II patients. Neither height nor BMI differed significantly among type I diabetic patients with or without $\mathrm{MM}$, although the influence of height upon the presence of MM became important for patients with either type of diabetes when the more conservative definition of MM (absolute plus relative criteria of median minus ulnar sensory latency $>0.8 \mathrm{~ms}$ ) was used. For both groups, patients fulfilling the conservative definition of MM were shorter than the remaining patients (type I, 168.9 vs. $172.0 \mathrm{~cm}, P=0.07$; type II, 163.8 vs. $172.7 \mathrm{~cm}, P=0.0005$ ).

Table 2 compares the frequency of MM by gender, BMI, and abnormal lower extremity nerve conduction frequencies for the type I and type II patient groups. In both groups, women were more likely than men to fulfill criteria for MM. In addition, there was a tendency for the frequency of MM to increase with increasing BMI, although the relationship reached statistical significance only for type II patients. There was no difference in the frequency of MM among patients separated into groups based upon sural and peroneal nerve conduction studies (normal or abnormal). Table 3 compares the nerve conduction results for patients fulfilling conventional criteria for MM with the results for the remaining patients by diabetes type. None of the lower limb measures differed significantly between patients with and without MM for patients with either type I or type II diabetes. For

Table 1. Descriptive statistics for patients fulfilling conventional criteria (absolute and relative) for median mononeuropathy.

\begin{tabular}{|c|c|c|c|c|c|c|}
\hline \multirow[b]{3}{*}{ Characteristic } & \multicolumn{6}{|c|}{ Type of diabetes } \\
\hline & \multicolumn{3}{|c|}{ Type I } & \multicolumn{3}{|c|}{ Type II } \\
\hline & $\begin{array}{l}\text { Abnormal } \\
(N=31)\end{array}$ & $\begin{array}{c}\text { Normal } \\
(N=124)\end{array}$ & P-value & $\begin{array}{l}\text { Abnormal } \\
(N=64)\end{array}$ & $\begin{array}{c}\text { Normal } \\
(N=195)\end{array}$ & $P$-value \\
\hline $\begin{array}{l}\text { Age }(y r) \\
\text { Duration of }\end{array}$ & $40.0(26.0,58.0)$ & $36.0(24.0,58.0)$ & 0.47 & $56.0(44.0,64.0)$ & $56.0(37.0,65.0)$ & 0.76 \\
\hline diabetes (yr) & $22.5(4.0,31.5)$ & $16.0(3.2,32.0)$ & 0.003 & $8.8(2.0,20.0)$ & $7.0(1.0 .20 .0)$ & 0.034 \\
\hline $\begin{array}{l}\text { Duration of neuropathy }(\mathrm{yr}) \\
\text { Glycosylated }\end{array}$ & $2.3(0.1,12.2)$ & $1.4(0.1,6.4)$ & 0.014 & $2.3(0.1,10.9)$ & $1.9(0.1,7.3)$ & 0.06 \\
\hline hemoglobin $(\%)$ & $10.2(7.4,13.8)$ & $9.8(7.3,13.9)$ & 0.48 & $10.0(6.9,14.5)$ & $9.7(6.5,14.1)$ & 0.16 \\
\hline Body weight (kg) & $74.8(50.6,110.7)$ & $73.9(54.9,99.5)$ & 0.44 & $89.2(60.8,132.2)$ & $87.5(63.5,119.3)$ & 0.28 \\
\hline Height $(\mathrm{cm})$ & $170.2(154.9,190.0)$ & $171.8(154.3,186.7)$ & 0.34 & $165.7(149.9,185.4)$ & $172.7(156.2,187.0)$ & 0.001 \\
\hline $\begin{array}{l}\text { Body mass index } \\
\left(\mathrm{kg} / \mathrm{m}^{2}\right)\end{array}$ & $24.9(20.2,39.3)$ & $24.3(20.1,33.4)$ & 0.12 & $32.5(24.5,40.9)$ & $29.1(23.1,39.6)$ & 0.0008 \\
\hline
\end{tabular}

Data expressed as: median (5th, 95th percentiles). 
Table 2. Frequencies of median mononeuropathy using conventional criteria (absolute and relative)

\begin{tabular}{|c|c|c|}
\hline \multirow[b]{2}{*}{ Characteristic } & \multicolumn{2}{|c|}{ Type of diabetes } \\
\hline & Type 1 & Type II \\
\hline $\begin{array}{l}\text { Gender } \\
\text { Female }\end{array}$ & $P=0.41$ & $P=0.0008^{*}$ \\
\hline Normal & 42 & 69 \\
\hline Abnormal & $13(23.6 \%)$ & $35(33.7 \%)$ \\
\hline \multicolumn{3}{|l|}{ Male } \\
\hline Normal & 82 & 126 \\
\hline Abnormal & $18(18.11 \%)$ & $29(18.7 \%)$ \\
\hline Body mass indext & $P=0.18$ & $P=0.004^{\star}$ \\
\hline \multicolumn{3}{|l|}{ Slender } \\
\hline Normal & 6 & 2 \\
\hline Abnormal & $1(14.3 \%)$ & $0(0.0 \%)$ \\
\hline \multicolumn{3}{|l|}{ Normal } \\
\hline Normal & 67 & 25 \\
\hline Abnormal & $15(18.3 \%)$ & $4(13.8 \%)$ \\
\hline \multicolumn{3}{|l|}{ Heavy } \\
\hline Normal & 32 & 67 \\
\hline Abnormal & $6(15.8 \%)$ & $13(16.3 \%)$ \\
\hline \multicolumn{3}{|l|}{ Obese } \\
\hline Normal & 19 & 101 \\
\hline Abnormal & $9(32.1 \%)$ & $47(31.8 \%)$ \\
\hline Right sural nerve conduction studies & $P=1.0$ & $P=0.44$ \\
\hline \multicolumn{3}{|l|}{ Normal } \\
\hline Normal & 38 & 65 \\
\hline Abnormal & $10(20.8 \%)$ & $18(21.7 \%)$ \\
\hline \multicolumn{3}{|l|}{ Abnormal } \\
\hline Normal & 85 & 127 \\
\hline Abnormal & $21(19.8 \%)$ & $46(26.6 \%)$ \\
\hline Left sural nerve conduction studies & $P=0.52$ & $P=0.53$ \\
\hline \multicolumn{3}{|l|}{ Normal } \\
\hline Normal & 41 & 58 \\
\hline Abnormal & $8(16.3 \%)$ & $16(21.6 \%)$ \\
\hline \multicolumn{3}{|l|}{ Abnormal } \\
\hline Normal & 83 & 134 \\
\hline Abnormal & $23(21.7 \%)$ & $48(26.4 \%)$ \\
\hline \multicolumn{3}{|l|}{ Peroneal motor nerve conduction } \\
\hline studies & $P=0.23$ & $P=1.0$ \\
\hline \multicolumn{3}{|l|}{ Normal } \\
\hline Normal & 63 & 112 \\
\hline Abnormal & $12(16.0 \%)$ & $38(25.3 \%)$ \\
\hline \multicolumn{3}{|l|}{ Abnormal } \\
\hline Normal & 59 & 80 \\
\hline Abnormal & $19(24.4 \%)$ & $26(24.5 \%)$ \\
\hline
\end{tabular}

Two-sided Fisher's Exact Test was used, otherwise specified. *Significant relationship with median mononeuropathy.

tMantel-Haenszel chi-square test

both groups, patients with MM had significantly lower median sensory amplitudes (type I, 12.1 vs. $22.7 \mu \mathrm{V}, P=0.0001$; type II, 10.3 vs. $16.4 \mu \mathrm{V}$, $P=0.0001$ ), and significantly longer F-wave latencies (type I, 30.1 vs. $28.7 \mathrm{~ms}, P=0.002$; type II, 30.1 vs. $29.6 \mathrm{~ms}, P=0.002$ ) than the remaining patients. Median motor conduction velocities were significantly slower for patients with MM. Median sensory conduction velocities were slower for patients with $M M$ but reached statistical significance only for patients with type II diabetes mellitus. As expected from the selection criteria, median distal latencies were significantly longer for patients with MM.

\section{Discussion}

In patients with mild diabetic neuropathy, the $23 \%$ frequency of MM using conventional electrodiag- nostic criteria seems high. However, we do not feel that the frequency is overestimated, as others have reported a prevalence of CTS in diabetic patients as high as $32 \%$, recognizing that the frequency of MM is not equivalent to the frequency of CTS. ${ }^{12}$ The cross-sectional study of diabetic neuropathy reported by Dyck and associates found electrodiagnostic evidence of asymptomatic MM in $22 \%$ of insulin-dependent and 29\% of non-insulindependent diabetic patients. ${ }^{12}$ The overall prevalence of $27 \%$ of asymptomatic MM is similar to the frequency we report, although we may have underestimated the frequency of MM in diabetic patients by including only standard evaluations, as well as by excluding patients with severe neuropathy and patients with greater than mild symptoms of CTS. Therefore, our data which are not derived from an epidemiologic study of CTS do not resolve the controversy related to the prevalence of asymptomatic MM in patients with diabetes mellitus. Nevertheless, had our population included a substantial number of patients with symptomatic CTS, it might be expected that the frequency of MM would have exceeded the prevalence of asymptomatic MM reported by Dyck and associates in their cross-sectional study. As an additional indication of the small proportion of patients with clinically significant CTS, only 1 of the 414 patients patients $(0.2 \%)$ underwent CTS surgery on the studied nerve during the 18-month follow-up period.

The electrodiagnostic measures we used are consistent with standard practice recommendations, and are among those most commonly used to confirm the diagnosis of CTS. ${ }^{1,3,14-16}$ The nerve conduction criteria for abnormality were established using 95th (conventional) and 99th (conservative) percentile values obtained from healthy, asymptomatic adults without occupational exposure to cumulative trauma. ${ }^{22}$ Previous studies have recognized the increased frequency of abnormal median conduction findings in diabetic patients. In addition, some have argued that the inclusion of median nerve results in criteria for diabetic neuropathy are inappropriate because of difficulty in apportioning the contribution of CTS and of neuropathy to electrophysiologic abnormalities when both are present. ${ }^{11}$ The results indicate that isolated median nerve abnormalities occur frequently in patients with mild diabetic neuropathy, even when patients with greater than mild CTS are excluded. Based on the distribution of median minus ulnar latencies, differences as great as $2.0 \mathrm{~ms}$ were within the 95 th percentile for this population of 
Table 3. Electrophysiology of patients fulfilling conventional criteria (absolute and relative) for median mononeuropathy.

\begin{tabular}{|c|c|c|c|c|c|c|}
\hline \multirow[b]{3}{*}{$\begin{array}{l}\text { Nerve conduction } \\
\text { study }\end{array}$} & \multicolumn{6}{|c|}{ Type of diabetes } \\
\hline & \multicolumn{3}{|c|}{ Type I } & \multicolumn{3}{|c|}{ Type II } \\
\hline & $\begin{array}{l}\text { Abnorma! } \\
(N=31)\end{array}$ & $\begin{array}{c}\text { Normal } \\
(N=124)\end{array}$ & $P$-value & $\begin{array}{l}\text { Abnormal } \\
(N=64)\end{array}$ & $\begin{array}{c}\text { Normal } \\
(N=195)\end{array}$ & $P$-value \\
\hline \multicolumn{7}{|l|}{$\overline{\text { Peroneal motor }}$} \\
\hline Amplitude (mV) & $3.5(0.9,7.0)$ & $3.9(0.9,9.2)$ & 0.07 & $3.6(1.0,9.1)$ & $4.2(1.2,8.9)$ & 0.74 \\
\hline Conduction velocity $(\mathrm{m} / \mathrm{s})$ & $40.5(35.8,49.8)$ & $40.3(31.0,48.8)$ & 0.34 & $40.5(33.1,50.0)$ & $40.6(33.2,50.0)$ & 0.57 \\
\hline Distal latency (ms) & $5.1(3.7,8.1)$ & $4.8(3.8,6.6)$ & 0.44 & $4.6(3.7,6.0)$ & $4.8(3.4,6.3)$ & 0.59 \\
\hline $\mathrm{F}$-wave latency (ms) & $54.2(40.6,64.4)$ & $53.2(45.0,67.6)$ & 0.21 & $53.1(42.5,72.4)$ & $55.1(43.2,63.2)$ & 0.77 \\
\hline \multicolumn{7}{|l|}{ Right sural } \\
\hline Amplitude $(\mu \mathrm{V})$ & $5.0(0.9,13.5)$ & $6.0(1.7,17.0)$ & 0.43 & $4.7(1.5,14.0)$ & $5.0(1.6,14.0)$ & 0.61 \\
\hline Conduction velocity $(\mathrm{m} / \mathrm{s})$ & $40.0(34.1,56.0)$ & $41.2(30.8,50.0)$ & 0.45 & $42.1(32.5,51.9)$ & $41.2(30.4,53.8)$ & 0.96 \\
\hline Distal latency (ms) & $4.3(3.2,4.9)$ & $4.3(3.5,5.4)$ & 0.47 & $4.1(3.4,5.4)$ & $4.1(3.3,5.3)$ & 0.66 \\
\hline \multicolumn{7}{|l|}{ Left sural } \\
\hline Amplitude $(\mu \mathrm{V})$ & $4.5(1.1,12.4)$ & $6.1(2.3,17.4)$ & 0.19 & $4.4(1.4,14.0)$ & $5.5(1.6,13.3)$ & 0.24 \\
\hline Conduction velocity $(\mathrm{m} / \mathrm{s})$ & $41.0(35.0,52.3)$ & $41.1(31.8,50.0)$ & 0.7 & $41.2(32.6,50.0)$ & $41.2(32.5,52.0)$ & 0.79 \\
\hline Distal latency (ms) & $4.2(3.3,5.2)$ & $4.2(3.4,5.2)$ & 0.6 & $4.1(3.3,5.0)$ & $4.2(3.4,5.2)$ & 0.7 \\
\hline \multicolumn{7}{|l|}{ Median motor } \\
\hline Amplitude (mV) & $8.3(2.6,13.5)$ & $9.0(4.3,13.5)$ & 0.55 & $7.7(2.2,12.5)$ & $7.6(3.6,13.4)$ & 0.34 \\
\hline Conduction velocity $(\mathrm{m} / \mathrm{s})$ & $51.4(42.0,57.8)$ & $53.0(45.7,58.9)$ & 0.06 & $49.8(42.6,58.3)$ & $51.8(45.1,58.3)$ & 0.006 \\
\hline Distal latency (ms) & $4.5(3.7,8.4)$ & $3.6(3.0,4.4)$ & 0.0001 & $4.6(3.8,5.8)$ & $3.7(3.0 .4 .5)$ & 0.0001 \\
\hline F-wave latency (ms) & $30.1(26.1,35.1)$ & $28.7(25.0,33.6)$ & 0.002 & $30.1(27.2,35.6)$ & $29.6(25.1,33.6)$ & 0.002 \\
\hline \multicolumn{7}{|l|}{ Median sensory } \\
\hline Amplitude $(\mu \mathrm{V})$ & $12.1(4.5,36.1)$ & $22.7(7.3,43.1)$ & 0.0001 & $10.3(3.3,23.4)$ & $16.4(6.3,39.2)$ & 0.0001 \\
\hline Conduction velocity $(\mathrm{m} / \mathrm{s})$ & $55.1(46.3,66.0)$ & $56.8(47.3,63.4)$ & 0.27 & $53.9(39.2,64.2)$ & $56.3(47.9,64.8)$ & 0.0008 \\
\hline Distal latency (ms) & $4.6(3.9,8.9)$ & $3.4(3.0,4.2)$ & 0.0001 & $4.4(4.0,5.7)$ & $3.5(2.9,4.2)$ & 0.0001 \\
\hline
\end{tabular}

Data expressed as: median (5th, 95th percentiles).

patients with mild diabetic neuropathy. Conventional criteria appear inappropriate to confirm the presence of CTS in diabetic patients, and cautious, conservative use of electrodiagnostic information should be emphasized in diagnosing CTS in diabetic patients with equivocal clinical findings. At the very least, these results suggest that patients with diabetic neuropathy may require special consideration when confirming the diagnosis of suspected CTS.

The reason for the greater frequency of $\mathrm{MM}$ in diabetic patients than in nondiabetic control subjects is unknown. One possibility is an increased susceptibility to focal trauma of diseased nerves, and some have suggested that focal entrapment may be the first manifestation of diabetic neuropathy. ${ }^{15}$ Therefore, any personal cofactors associated with CTS, such as exposure to repetitive activities or obesity, could produce focal nerve injury at points of increased vulnerability more easily in patients with diabetic neuropathy than in normal subjects. An increased frequency of MM with increasing evidence of an underlying neuropathy would support this possibility. Stratification of patients into groups of differing severity of neuropathy based upon sural or peroneal nerve conduction abnormalities did not influence the frequency of MM. Comparison of nerve conduction results between patients fulfilling conventional criteria for $\mathrm{MM}$ and the remaining patients demonstrated no significant differences for any of the peroneal or sural measurements, further indicating that the magnitude of the underlying neuropathy could not explain the presence of the MM. The only nerve conduction differences related to median nerve measures. All were consistent with focal slowing and loss of large myelinated fibers producing reduced amplitudes (sensory), reduced conduction velocities, and prolonged $\mathrm{F}$-wave latencies.

It also is possible that patients with diabetic neuropathy experience less paresthesias and less pain in association with median nerve compression and therefore are less likely to have clinically evident CTS than otherwise normal individuals with similar degree of median nerve compression. This decreased awareness could mask clinical recognition of CTS and could account for the greater frequency of $\mathrm{MM}$ in diabetic patients than in control subjects, although the frequency of asymptomatic MM under these conditions would seemingly increase in proportion to the degree of underlying neuropathy, a finding we could not demonstrate.

Our finding that the presence of MM was significantly associated with the duration of diabetes mellitus but not the type of diabetes or age is consistent with the observations of Dyck and associates. ${ }^{12}$ Unlike our current results, they found no relationship between MM and gender, whereas we found a higher frequency in female than in male patients. Gender appeared to influence the diag- 
nosis in a retrospective-review of 261 patients referred for electrodiagnostic evaluation and found to have MM; in that study, $31 \%$ of female patients compared with $23 \%$ of male patients had abnormal results. ${ }^{24}$ Others have identified a higher frequency of CTS in female than in male patients, although this difference may relate to other covariates of nerve conduction measures, including body size. $^{23}$

Several investigators found that patients with CTS are heavier and shorter than the general population. ${ }^{7,9,13,17,23}$ Others have identified BMI as an important cofactor, with obese patients (BMI > 29) 2.5 times more likely than slender patients $(\mathrm{BMI}<$ 20 ) to have electrodiagnostic evidence of $\mathrm{MM}$, although the basis of the association is not understood. ${ }^{24}$ Overall, the findings in the general population relating personal cofactors to development of MM are similar to those found for patients with type II diabetes mellitus. The failure to identify similar associations in patients with type I diabetes mellitus is unexplained. The trends associating height to MM were in a direction similar to that for the findings reported above and became significant when the more conservative definition of MM was used. The failure to identify a significant relationship between BMI and MM in patients with type I diabetes mellitus may reflect the distribution of BMI in this patient group.

We used latency criteria of MM that classified patients as normal or abnormal. Because some patients had borderline results (normal or abnormal), we attempted to confirm our findings by identifying subgroups of patients who fulfilled conventional criteria for all three trials, as well as patients who did not fulfill criteria in any of the three trials. We felt that these two groups were most representative of patients with and without conventional electrodiagnostic evidence of MM, respectively. Additional analyses with these selective patient groups demonstrated results similar to those reported above. For type II patients, the relationships between MM and gender, and between MM and BMI, although still in the same direction, were no longer statistically significant. Patients classified as having MM, but who had inconsistent results on subsequent trials, resembled patients who did not fulfill criteria for MM. This finding is not surprising, because these were the patients with borderline results who typically would have additional studies (e.g., midpalmar studies) and would most likely be classified as having equivocal evidence of MM.

Some of our results could reflect the selection criteria that attempted to identify a relatively homogenous group of patients with mild diabetic neuropathy. Confirmation of these findings in the general diabetic population requires a more diverse group of patients with respect to diabetic neuropathy.

\section{REFERENCES}

1. AAEM Quality Assurance Committee (Jablecki CK, Andary MT, So YT, Wilkins DE, Williams FH): Literature review of the usefulness of nerve conduction studies and electromyography for the evaluation of patients with carpal tunnel syndrome. Muscle Nerve 1993;16:1392-1414.

2. Albers JW, Brown MB, Sima AAF, Greene DA, for the Tolrestat Study Group for EDIT (Early Diabetes Intervention Trial): Nerve conduction measures in mild diabetic neuropathy: in the early diabetes intervention trial (EDIT) the effects of age, sex, type of diabetes, disease duration, and anthropometric factors. Neurology (in press).

3. American Academy of Neurology, American Association of Electrodiagnostic Medicine, American Academy of Physical Medicine and Rehabilitation: Practice parameter for electrodiagnostic studies in carpal tunnel syndrome (summary statement). Neurology 1993;43:2404-2405.

4. American Diabetes Association: Report and recommendations of the San Antonio conference on diabetic neuropathy. Muscle Nerve 1988;11:661-667.

5. Anderson JV, Rafferty AP: Overweight, in Health Risk Behaviors-1991. Lansing, MI, Michigan Department of Public Health, 1992.

6. Asbury AK, Porte D (committee co-chairmen): Proceedings of a consensus development conference on standardized measures in diabetic neuropathy. Neurology 1992;42: 1823-1839.

7. Cannon LJ, Bernacki EJ, Walter DS: Personal and occupational factors associated with carpal tunnel syndrome. $J$ Occup Med 1982;23:255-258.

8. Daube JR: Electrophysiologic testing in diabetic neuropathy, in Dyck PJ, Thomas PK, Asbury AK, Winegrad AI, Porte D Jr (eds): Diabetic Neuropathy. Philadelphia, Saunders, 1987, pp 162-176.

9. Dieck GS, Kelsey JL: An epidemiologic study of the carpal tunnel syndrome in an adult female population. Prevent Med 1985;14:63-69.

10. Dyck PJ: Detection, characterization, and staging of polyneuropathy: assessed in diabetes. Muscle Nerve 1988;11: 21-32.

11. Dyck PJ, Karnes JL, O'Brien PC: The Rochester diabetic neuropathy study: reassessment of tests and criteria for diagnosis and staged severity. Neurology 1992;42:1164-1170.

12. Dyck PJ, Kratz KM, Karnes JL, Litchy WJ, Klein R, Pach JM, Wilson DM, O'Brien PC, Melton LJ, Service FJ: The prevalence by staged severity of various types of diabetic neuropathy, retinopathy, and nephropathy in a population-based cohort: the Rochester Diabetic Neuropathy Study. Neurology 1993;43:817-824.

13. Falck B, Aarnia P: Left-sided carpal tunnel syndrome in butchers. Scand J Work Environ Health 1983;9:291-297.

14. Jackson D, Clifford JC: Electrodiagnosis of mild carpal tunnel syndrome. Arch Phys Med Rehabil 1989;70:199-204.

15. Johnson EW: Sixteenth annual AAEM Edward H. Lambert lecture. Electrodiagnostic aspects of diabetic neuropathies: entrapments. Muscle Nerve 1993;16:127-134.

16. Kimura J: Assessment of individual nerves, in Electrodiagnosis in Diseases of Nerve and Muscle: Principles and Practice. Philadelphia, F. A. Davis, 1983, pp 105-141.

17. Nathan PA, Keniston RC, Myers LD, Meadows KD: Obesity 
as a risk factor for slowing of sensory conduction of the median nerve in industry. $J$ Occup Med 1992;34:379-383.

18. National Diabetes Data Group: Classification and diagnosis of diabetes mellitus and other categories of glucose intolerance. Diabetes 1979;28:1039-1057.

19. Protocol No. 709A-304/306-US. A Double-Blind, PlaceboControlled, Randomized Study of the Effects of Tolrestat on Peripheral Nerve Morphology and Biochemistry in Patients with Diabetic Peripheral Sensorimotor Neuropathy. Philadelphia, Wyeth-Ayerst Research, 1991.

20. Redmond MD, Rivner MH: False positive electrodiagnostic tests in carpal tunnel syndrome. Muscle Nerve 1988;11: 511-517.

21. Report of the Quality Standards Subcommittee of the
American Academy of Neurology: Practice parameter for carpal tunnel syndrome (summary statement). Neurology 1993;43:2406-2409.

22. Stetson DS, Albers JW, Silverstein BA, Wolfe RA: Effects of age, sex, and anthropometric factors on nerve conduction measures. Muscle Nerve 1992;15:1095-1104.

23. Vessey MP, Villard-Mackintosh LV, Yeates D: Epidemiology of carpal tunnel syndrome in women of childbearing age. Findings in a large cohort study. Int J Epidemiol 1990; 19:655-659.

24. Werner RA, Albers JW, Franzblau A, Armstrong TJ: The relationship between body mass index and the diagnosis of carpal tunnel syndrome. Muscle Nerve 1994; 17:632-636. 